\title{
High Pressure Cell for Edge Jumping X-ray Absorption Spectroscopy: Applications to industrial liquid sulfidation of hydrotreatment catalysts
}

\author{
Lesage, C. ${ }^{1,2}$; Devers, E. ; Legens, C. ${ }^{1}$; Fernandes, G. ${ }^{1}$; Roudenko, O. ${ }^{2}$; Briois, V. ${ }^{2}$ \\ ${ }^{1}$ IFP Energies nouvelles, Rond-point de l'échangeur de Solaize BP3, 69360 Solaize \\ ${ }^{2}$ Synchrotron SOLEIL L'orme des Merisiers, 91192 Gif-sur-Yvette Cedex, France
}

Corresponding authors: clement.lesage@ifpen.fr, christele.legens@ifpen.fr, elodie.devers@ifpen.fr

\begin{abstract}
A new analytical cell to perform liquid sulfidation of HDS catalysts in industrial conditions was developed. It enables the alternate recording of time-resolved Mo and Co K edges X-ray Absorption spectra of bimetallic catalysts under high pressure (30 bar) and temperature $\left(350^{\circ} \mathrm{C}\right)$ during the same reaction. Thanks to this cell, a comparative study of the species formed upon gas ( 1 bar, $15 \% \mathrm{H}_{2} \mathrm{~S} / \mathrm{H}_{2}$ ) and liquid sulfidation (30 bar, $\mathrm{H}_{2} /$ gas oil/4\% DMDS) of a CoMoP/Al $\mathrm{O}_{3} \mathrm{HDS}$ catalyst was carried out, together with a discussion on the evolution of the concentration profiles upon activation. Different Mo and Co-based chemical species are involved during gas and liquid sulfidation. On one hand, in industrial liquid sulfidation, polymolybdate species are transformed into depolymerized oxides, then into an oxysulfide, a $M_{0} S_{x}$ species and finally into $M_{0}$. On the other hand, gas sulfidation skips the depolymerization process because of the immediate supply of $\mathrm{H}_{2} \mathrm{~S}$ at the beginning of the process and proceeds under a stepwise transformation of oxide into oxysulfide, itself into $\mathrm{MoS}_{3}$ species and finally into $\mathrm{MoS}_{2}$. Cobalt species under gas sulfidation goes through a $\mathrm{CoS}_{2}$ intermediate whereas in liquid sulfidation, it is a 4-fold coordinated Co oxide species. Irrespective to the activation route, mixture of $\mathrm{Co}_{9} \mathrm{~S}_{8}$ and $\mathrm{CoMoS}$ is obtained at advanced sulfidation stage $\left(\mathrm{T}>200^{\circ} \mathrm{C}\right)$.
\end{abstract}

\section{Graphical Abstract}

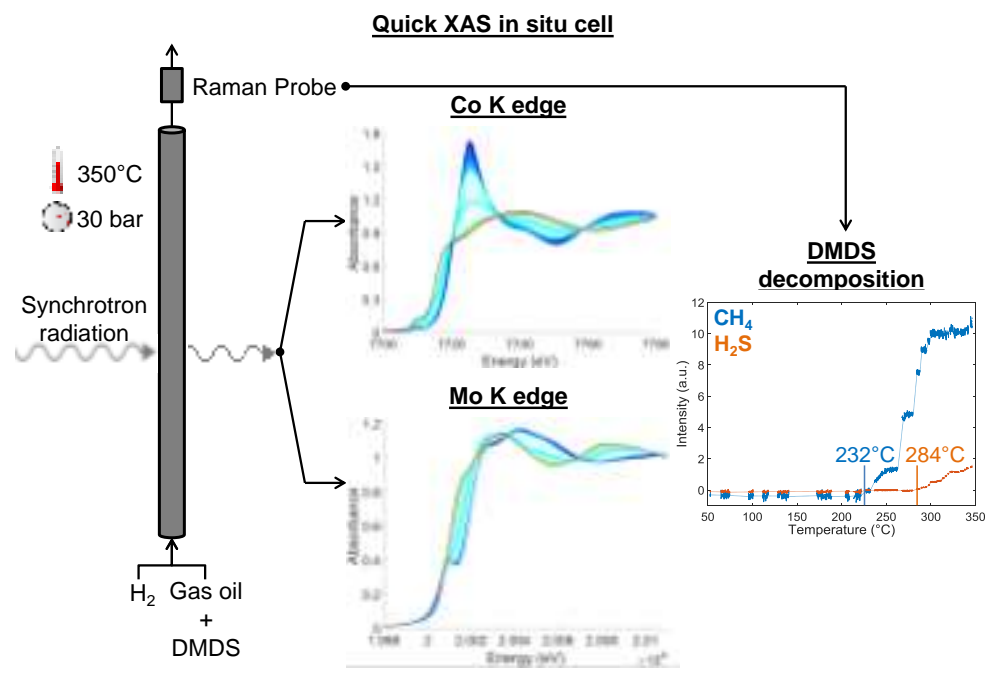




\section{Highlights}

- A high pressure cell has been developed to study the liquid sulfidation of HDS catalyst by X-ray Absorption Spectroscopy

- Co and Mo local orders are studied alternatively during the same reaction

- The sulfidation mechanism depends on the activation process

- The sulfidation of Co and Mo in liquid phase mainly occurs when DMDS is decomposed into $\mathrm{H}_{2} \mathrm{~S}$ between $225^{\circ} \mathrm{C}$ and $350^{\circ} \mathrm{C}$. Gas sulfidation starts at room temperature and is completed at $400^{\circ} \mathrm{C}$

\section{Keywords}

Quick-XAS, Liquid sulfidation, high pressure, Analytical reactor, Glassy carbon, Gas

sulfidation, CoMoP HDS catalyst

\section{Introduction}

Air quality has become a main issue since the 1970's. Environmental regulations were established to reduce gas exhaust emissions of gasoline engines like carbon monoxide, nitrogen oxide and particulates but also sulfur content and other impurities in fuels, leading refiners to improve their processes such as hydrodesulfurization (HDS). This step is crucial to reduce the sulfur content of gas oil distillates. Indeed, sulfur compounds are not only generators of $\mathrm{SO}_{x}$ emissions during gas oil combustion but are also poisons for catalytic converters.

HDS catalysts are prepared from metal oxide precursors deposited on a porous alumina, which require a sulfidation step to be active. Usually these precursors are composed of a group VI transition metal, like molybdenum or tungsten, promoted by a group IX and X transition metal, such as nickel or cobalt. For industrial application, a CoMo catalyst is composed of 8 to $15 \mathrm{wt} \%$ of $\mathrm{Mo}$ and 1 to $5 \mathrm{wt} \%$ of Co supported on a $\mathrm{y}$-alumina with a specific surface around $250 \mathrm{~m}^{2} / \mathrm{g}[1,2]$. The addition of phosphorous in the impregnation solution leads to a better dispersion of the heteropolyanions on the support and, thus, enhances the HDS catalytic activity [3].

The sulfidation step can be carried out either in gas phase with $\mathrm{H}_{2}$ and $\mathrm{H}_{2} \mathrm{~S}$ or in gas-liquid phase with $\mathrm{H}_{2}$, gas oil and a light organic compound containing sulfur such as dimethyldisulfide (DMDS). These processes are called thereafter "gas activation" and "liquid activation", respectively. The liquid sulfidation lasts about 30 hours at $30-40$ bars and $350^{\circ} \mathrm{C}$. The thermal decomposition of the sulfur containing compound arising usually in the temperature range around $200^{\circ} \mathrm{C}$ is used to provide $\mathrm{H}_{2} \mathrm{~S}$. The gas sulfidation takes about 2 to 4 hours at $400^{\circ} \mathrm{C}$ and atmospheric pressure with a direct supply of $\mathrm{H}_{2} \mathrm{~S}$. In refineries, catalysts are usually sulfided in liquid phase using DMDS, whereas at the laboratory scale, for operating easiness considerations, most of the studies are performed in gas phase $[4,5]$.

Differences were observed between liquid and gas sulfidations on the activation mechanism. Frizi et al. [5,6] investigated by Mo 3d and Co 2p XPS (X-ray Photoelectron Spectroscopy) 
the changes for a calcined commercial catalyst containing $18 \mathrm{wt} \% \mathrm{MoO}_{3}$ and $3.5 \mathrm{wt} \% \mathrm{CoO}$ sulfided either at atmospheric pressure under $10 \%$ of $\mathrm{H}_{2} \mathrm{~S} / \mathrm{H}_{2}$ or at 35 bar in a $\mathrm{H}_{2} / D M D S / g a s$ oil mixture. Different temperatures for the onset of sulfidation were reported depending on the activation route. In gas phase, Co sulfidation starts at $50^{\circ} \mathrm{C}$ and ends rapidly at $110^{\circ} \mathrm{C}$ whereas the sulfidation of $\mathrm{Mo}$ is not completed until $350^{\circ} \mathrm{C}$. In liquid phase, molybdenum and cobalt sulfidations occur between $110^{\circ} \mathrm{C}$ and $220^{\circ} \mathrm{C}$. It ends at $280^{\circ} \mathrm{C}$ for Co with no further evolution of XPS signal whereas Mo 3d XPS signal for sulfidic species is still evolving up to $350^{\circ} \mathrm{C}$. In the same time, Eijsbouts et al. [7] focused on the activation route effect on the morphology of the sulfided phase by TEM-EDX (Transmission Electron Microscopy with Energy Dispersive $X$ ray) and XRD (X Ray Diffraction). Commercial CoMo catalysts (1.7 Co atoms $/ \mathrm{nm}^{2}$ and 3.9 or $4.6 \mathrm{Mo}$ atoms $/ \mathrm{nm}^{2}$ ) were sulfided at atmospheric pressure under $\mathrm{H}_{2} \mathrm{~S} / \mathrm{H}_{2}$ and at 30 bar under a mixture of DMDS/SRGO (Straight Run Gas Oil). Liquid sulfided catalysts contained single $\mathrm{MoS}_{2}$ layers whereas, after $\mathrm{H}_{2} \mathrm{~S} / \mathrm{H}_{2}$ gas sulfidation, some $\mathrm{MoS}_{2}$ stacks appear.

Most of the studies [5-7] carried out on the sulfidation of HDS catalysts characterized step wisely the sulfidation operations and the involved mechanisms. However the monitoring of the reaction using XPS or TEM needs to be stopped at defined temperatures in order to measure the catalysts into specific conditions of pressure and temperature required by the techniques. It is even more complicated for liquid sulfidation because the catalyst needs to be free of gas oil to be analysed by XPS or TEM. Therefore, the in situ characterization, in real industrial conditions, is impossible with these commonly used techniques. To get rid of the sampling issues, there is a need of in situ characterization techniques. $\mathrm{X}$ ray Absorption Spectroscopy (XAS) is an elemental specific technique which focuses on the local order and electronic structure of the absorbing atom and which takes advantages of the high penetrating power of X-rays to be carried out in situ. Provided that measurements are performed with adapted time-resolution, XAS is a choice technique to determine reaction mechanisms and to identify the nature of chemical intermediates. Thanks to chemometric methods, Quick-XAS beamlines and dedicated analytical cells, Rochet et al. [8,9] characterised the gas sulfidation mechanism of CoMo and Mo based catalysts by a time resolved XAS study coupled with Raman spectroscopy. However, the gas sulfidation is not representative of the industrial conditions. Furthermore, the activation process determines the formation of the active phase and, thus, the further efficiency of the catalyst. Thence, an improvement of the industrial catalyst involves a better understanding of the industrial liquid sulfidation. To the best of our knowledge, the first XAS analytical cell to study the liquid sulfidation of HDS catalysts with a model feedstock in reaction conditions (20 bar, $\left.350^{\circ} \mathrm{C}\right)$ close to the industrial ones $\left(30\right.$ bar, $\left.350^{\circ} \mathrm{C}\right)$ was recently designed by Van Haandel et al. [10]. However, this cell does not allow the characterization of the bimetallic catalyst during a unique reaction at both $\mathrm{Co} \mathrm{K}$ edge and Mo $\mathrm{K}$ edge making the comparison of the catalyst fate and especially the potential synergetic effect on the sulfidation by one element to the second, less straightforward to identify.

In this paper is reported a detailed description of the cell and its use at the ROCK beamline [11] for a Quick-XAS study of the liquid sulfidation of a CoMoP catalyst under a real gas oil feedstock at 30 bar and $350^{\circ} \mathrm{C}$. This cell is suitable for the characterization, during the same reaction, of the local order around Mo and its Co promoter. The results obtained with this cell will be compared to those obtained for a similar catalyst sulfided under gas phase at atmospheric pressure. Using the unique "edge jump" capability of the ROCK beamline 
[11,12] and the chemometric Multivariate Curve Regression with Alternating Least Square fitting (MCR-ALS) approach [8], the intermediates species involved in the reaction mechanism will be isolated and simulated for identification. Finally, we will highlight the main differences in mechanisms between the liquid and gas sulfidation.

\section{Experimental}

\subsection{Catalysts preparation and Ex situ characterization}

A CoMoP $/ \mathrm{Al}_{2} \mathrm{O}_{3}$ catalyst is synthetized by incipient wetness impregnation of $\mathrm{Y}$-alumina extrudate (surface area: $270 \mathrm{~m}^{2} / \mathrm{g}$ ) with a solution of $\mathrm{MoO}_{3}$ (sigma-Aldrich, purity: $99.93 \%$ ), $\mathrm{Co}(\mathrm{OH})_{2}$ (sigma-Aldrich, purity: 96.21\%), $\mathrm{H}_{3} \mathrm{PO}_{4}$ (sigma-Aldrich, purity: 85\%) and distilled water. The amount of $\mathrm{MoO}_{3}$ is $22 \mathrm{wt} \%$ and the $\mathrm{Co} / \mathrm{Mo}$ and $\mathrm{P} / \mathrm{Mo}$ molar ratios are 0.4 and 0.55 , respectively. The catalyst is maturated in a saturated water atmosphere at room temperature (RT) for $24 \mathrm{~h}$ and finally dried at $120^{\circ} \mathrm{C}$ for 6 hours. The dried catalyst is characterised by Raman spectroscopy with a confocal Renishaw InVia Raman microscope using the $532 \mathrm{~nm}$ excitation wavelength provided by a double frequency Nd-YAG laser and equipped with a holographic grating with 2400 lines/nm, a dielectric filter, an EasyConfocal Renishaw device and a 50x objective. Several positions are analysed on the same extrudate to check the homogeneity of the impregnated species with the following parameters: laser power: $0.75 \mathrm{~mW}$, accumulation: 2 , spectra accumulation: $100 \mathrm{~s}$. The sulfided catalysts are characterized by Transmission Electron Microscopy (TEM). Measurements are carried out in bright field mode with a FEG TECNAI TEM operating at $200 \mathrm{keV}$. The catalyst is crushed, diluted in ethanol and deposited on a fine copper grid covered by carbon. Ethanol is then evaporated and TEM analysis is performed. The distribution profiles of the slab size and stacking are obtained by measuring 200 particles. The average values are calculated using a log-normal function. The $\mathrm{MoS}_{2}$ slabs with a size below $1 \mathrm{~nm}$ are not detected.

\subsection{In situ characterization}

\subsubsection{XAS reactor design}

The specifications guiding the XAS reactor design are: 1) analytical cell allowing XAS measurements in transmission mode at energy higher than $7 \mathrm{keV}$ for characterization of Mo and Co chemical elements and 2) operation at high pressure (35 bar) and high temperature $\left(350^{\circ} \mathrm{C}\right)$. It is composed of a consumable sample holder, a gas/liquid distribution system and a control panel.

The sample holder is a glassy carbon tube (length: $150 \mathrm{~mm}$, outer diameter: $4.7 \mathrm{~mm}$ and inner diameter: $2.1 \mathrm{~mm}$ ) which can be used up to 35 bar. The cumulative wall thickness of $2.6 \mathrm{~mm}$ enables a transmission of $14 \%$ at the Co $\mathrm{K}$ edge $(7709 \mathrm{eV})$ and $92 \%$ at the Mo $\mathrm{K}$ edge $(20003.9 \mathrm{eV})$. The catalyst is introduced as a powder in a reaction area of $30 \mathrm{~mm}$ centred in the tube. It is held in position on each side by $5 \mathrm{~mm}$ of quartz wool in contact with a thermocouple. The reactor is heated by a tubular stainless steel oven of $8 \mathrm{~cm}$ length. Heating up is supplied with a direct current with a voltage varying from 0 to $2 \mathrm{~V}$ and an amperage up to $100 \mathrm{~A}$. In the middle of the oven, two $10 \mathrm{~mm}$ length and $2 \mathrm{~mm}$ wide rectangular apertures were drilled to enable the X-rays to pass through the glassy carbon 
tube and the sample. The oven is isolated by a mineral fibre ribbon with a density of 128 $\mathrm{kg} / \mathrm{m}^{3}$ as shown in Figure 1. The reactor is centred in the oven by quartz or alumina inserts to prevent any contact between the oven and the glassy carbon tube in order to avoid any electrical shortcut. The connection between the reactor and the reactant supply is done with two homemade stainless steel blocks described in Figure 2. The reactor is sealed by a vespel $(60 \%)$ / graphite $(40 \%)$ ferrule pressed into the block body by a metallic insert and a connector. Figure 3 presents a slide view of the reactor after being installed in the cell.

Insert Figure 1.

Insert Figure 2.

Insert Figure 3.

A scheme of the gas/liquid distribution system is shown in Figure 4. It is composed of two gas lines for $\mathrm{H}_{2}$ and $\mathrm{N}_{2}$, one liquid line for the gas oil and DMDS mixture and a membrane backpressure regulator (Equilibar ZF). The gas flows are controlled with mass flow controller and the liquid flow with a PhD ultra 4400 syringe pump provided by Harvard apparatus. The fluid circulation is up flow in the reactor. A Nanodac Eurotherm controller sets the gas flow, the temperature of the reactor and records the pressures at the inlet and outlet of the cell. Ramps and stage can be programmed in the controller which provides an alternating current transformed by a stabilized power supply "SM3300 series" from Delta Elektronica into a direct current. The temperature is regulated by a thermocouple at the inlet of the cell. A second thermocouple is at the exit of the catalytic bed to control the homogeneity of the temperature. A Process Elite Flow Cell Ballprobe ${ }^{\circledR}$ developed by Marqmetrix is connected to the outlet of the reactor to analyse by Raman spectroscopy the gas products in the gas/liquid mixture, especially the relative concentration evolution of $\mathrm{H}_{2} \mathrm{~S}$ and $\mathrm{CH}_{4}$ resulting from the DMDS decomposition.

Insert Figure 4.

\subsubsection{XAS and Raman data acquisition}

In situ XAS data were recorded at the Quick-XAS ROCK beamline [11] of the SOLEIL synchrotron. Two equivalent Quick-XAS monochromators are equipped with two independent channel-cuts ( $\mathrm{Si}(111)$ and $\mathrm{Si}(220))$, each mounted on a cam driven tilt table that oscillates periodically around a fixed Bragg angle [12]. The angular amplitude is chosen by the user depending on the energy domain that is required for EXAFS analysis. An oscillation amplitude of $2.2^{\circ}$ is required for covering with the $\mathrm{Si}(111)$ channel-cut more than $1200 \mathrm{eV}$ above the Co $\mathrm{K}$ edge whereas, at the Mo $\mathrm{K}$ edge, using the $\mathrm{Si}(220)$ channel-cut with an amplitude of $0.9^{\circ}$ is enough. The oscillation frequency is fixed at $2 \mathrm{~Hz}$ leading to the acquisition of a spectrum with increasing Bragg angles every $250 \mathrm{~ms}$. The ionization chambers (ICs) were filled with a mixture of $50 \%$ of nitrogen and $50 \%$ of argon for the Mo data recording and $100 \%$ of nitrogen for the ones at the Co $\mathrm{K}$ edge. Thanks to the edge jumping capabilities of the beamline [11,12], both Co and Mo were alternatively characterized during the in situ liquid sulfidation. The acquisition sequence is presented in Figure 5. 600 spectra with increasing Bragg angles were acquired during $305 \mathrm{~s}$ at the Co $\mathrm{K}$ edge and then merge to increase the signal/noise ratio. At the Mo K edge, the acquisition lasts $37 \mathrm{~s}$ and 60 spectra with increasing Bragg angles were merged. The period of $35 \mathrm{~s}$ between Mo and Co $\mathrm{K}$ edge data recording is the time required for exchanging the $\mathrm{Si}(220)$ based monochromator by the $\mathrm{Si}(111)$ one, the $\mathrm{Pd}$ stripe of the harmonic rejection mirrors (Mo K edge) by the $\mathrm{B}_{4} \mathrm{C}$ 
one (Co K edge) and the set of 3 energy-optimized ICs. Thus, we could obtain one merged spectra per edge every $2.86^{\circ} \mathrm{C}$ at the early stage of sulfidation which uses a ramp at $25^{\circ} \mathrm{C} / \mathrm{h}$ up to $190^{\circ} \mathrm{C}$ and every $1.37^{\circ} \mathrm{C}$ with a ramp at $12^{\circ} \mathrm{C} / \mathrm{h}$ used at higher sulfidation temperature. Raman spectra of the products obtained at the gas outlet were acquired through the Raman gas probe connected to the RXN1 spectrometer (Kaiser Opical Systems Inc.) available at the beamline, with the following parameters: laser wavelength: $785 \mathrm{~nm}$, laser power: $340 \mathrm{~mW}$, acquisition time: $1 \mathrm{~s}$, accumulation: 5, sampling frequency: $30 \mathrm{~s}$. Because of the gas/liquid mixture, Raman spectra may show either the gas phase or the liquid/gas mixture. The spectra of the mixture are not processed because the strong scattering Raman signal of gas oil hides the characteristic Raman lines of $\mathrm{H}_{2} \mathrm{~S}$ and $\mathrm{CH}_{4}$.

Insert Figure 5.

\subsubsection{Liquid sulfidation conditions}

The crushed catalyst is diluted into diamond powder in chosen proportion to optimise the transmission at the Co $\mathrm{K}$ edge considering the catalyst composition. In such condition, the reactor contains $21.8 \mathrm{mg}$ of crushed catalyst diluted in $196.3 \mathrm{mg}$ of diamond powder. The reactor is, first, filled with $\mathrm{N}_{2}$. The pressure is then increased at 30 bar, a leak detection is made and the reactor is filled with $\mathrm{H}_{2}$. The wetting of the catalyst bed is done at $50^{\circ} \mathrm{C}$ under the real feedstock composed of $96 \mathrm{wt} \%$ of a gas oil containing $0.128 \mathrm{wt} \%$ of sulfur and $4 \mathrm{wt} \%$ of DMDS to reach a total sulfur concentration of $2.84 \mathrm{wt} \%$ and an overall $\mathrm{H}_{2} \mathrm{~S}$ pressure of 2.1 bar. This step lasts 2 hours with a $\mathrm{H}_{2}$ flow of $3 \mathrm{~mL} / \mathrm{min}$ and a liquid flow of $50 \mu \mathrm{L} / \mathrm{min}$. Then, the sulfidation begins with a first ramp from $50^{\circ} \mathrm{C}$ to $190^{\circ} \mathrm{C}$ at $25^{\circ} \mathrm{C} / \mathrm{h}$ and a second ramp till $350^{\circ} \mathrm{C}$ at $12^{\circ} \mathrm{C} / \mathrm{h}$. Finally a stage of 8 hours is carried out at $350^{\circ} \mathrm{C}$. During the sulfidation, the $\mathrm{H}_{2}$ flow and the liquid flow are set, respectively at $0.10 \mathrm{~mL} / \mathrm{min}$ and $0.41 \mu \mathrm{L} / \mathrm{min}$ in order to keep a liquid hourly space velocity at $1 \mathrm{~h}^{-1}$ and a $\mathrm{H}_{2} / \mathrm{Hydrocarbon}$ ratio of 250 . At the end of the stage, the temperature is decreased to RT under $\mathrm{H}_{2}$ and liquid feed. At each step, XAS spectra were continuously recorded at both edges.

\subsubsection{Gas sulfidation}

For comparison purpose with our results obtained in liquid sulfidation, a gas sulfidation was carried out in the cell described in paragraph 3.1 of reference [13] and also monitored at the $\mathrm{Co}$ and Mo K edges at the ROCK beamline. $18 \mathrm{mg}$ of dried CoMoP catalyst were diluted in $18 \mathrm{mg}$ of boron nitride and loaded in the $2 \mathrm{~mm}$-thick sample holder between two $500 \mu \mathrm{m}$-thick graphite foils. The gas sulfidation started with a ramp from $25^{\circ} \mathrm{C}$ to $400^{\circ} \mathrm{C}$ at $120^{\circ} \mathrm{C} / \mathrm{h}$ under a mixture of $15 \mathrm{v} \%$ of $\mathrm{H}_{2} \mathrm{~S}$ in $\mathrm{H}_{2}(\mathrm{HVS}=10 \mathrm{~L} / \mathrm{h} / \mathrm{g})$ under atmospheric pressure. Then isothermal heating at $400^{\circ} \mathrm{C}$ lasted 2 hours. The acquisition time for XAS was similar at each edge and equal to $45 \mathrm{~s}$ leading to a merged spectrum (sum of 60 spectra with increasing Bragg angles) at each edge every $5.3^{\circ} \mathrm{C}$. Finally, when sulfidation was completed, a last acquisition was made at RT under $\mathrm{H}_{2} \mathrm{~S} / \mathrm{H}_{2}$.

\subsubsection{XAS data treatment}

The collected spectra are, first, processed through a graphical interface developed at SOLEIL synchrotron and dedicated to the data obtained at the ROCK beamline. Using the extract_gui graphical user interface (Fig. S1. in Supporting information (SI)), the data are merged in order to improve the signal over noise ratio after energy interpolation according to 
an energy grid specific to each edge. A second graphical user interface, normal_gui (Fig. S2. in $\mathrm{SI}$ ), is used i) to define an absolute energy scale for the data using the derivative of the metal foil recorded simultaneously to the data by associating the maximum of the first derivative of the metal foil to the literature value at $20003.9 \mathrm{eV}$ for Mo [14] and $7709 \mathrm{eV}$ for Co [15]; ii) to align in the absolute energy all the data and iii) to normalize the data using the same parameters for pre-edge linear background extraction and post-edge polynomial fitting. These interfaces allow the users to quickly process a large amount of data suitable for building the data matrix arranged so that each horizontal row contains the spectra recorded at the different times of the reaction and used for further multivariate analysis. The normalised data are analysed with two chemometric methods, Principal Component Analysis (PCA) and Multivariate Curve Resolution with Alternating Least Squares in order to determine the different intermediates involved and their concentration profiles. The MCRALS program used in this work was the MCR-ALS 2.0 GUI developed by the group of Roma Tauler $[16,17]$ for Matlab environment. The application of these chemometric methods to the XAS analysis of the HDS catalyst activation was already described by Rochet et al. [8] and a detailed presentation can be found in SI. For further EXAFS analysis involving EXAFS extraction, Fourier Transformations (FT), EXAFS simulation, experimental or MCR-ALS XAS spectra were processed with the Athena software (version: 0.8.056) and Artemis software (version 0.8.012). $\mathrm{S}_{0}^{2}$ and enot were determined by fitting $\mathrm{MoS}_{2}$ [18], $\mathrm{HMA}$ [19] and $\mathrm{MoO}_{3}$ [20] references according to their respective crystallographic structures for the Mo $\mathrm{K}$ edge and $\mathrm{CoS}_{2}$ [21] and $\mathrm{Co}(\mathrm{OH})_{2}$ [22] for the Co $\mathrm{K}$ edge. These parameters were then fixed respectively to 0.96 and $20011.3 \mathrm{eV}( \pm 3.1 \mathrm{eV})$ at the Mo K edge and 0.73 and $7718.6 \mathrm{eV}( \pm$ $2.9 \mathrm{eV}$ ) at the Co $\mathrm{K}$ edge. The $\mathrm{k}$ ranges for all the simulated spectra are presented in Table 1. in SI.

\section{Results}

\subsection{Liquid sulfidation}

Figure 6 A. and B. display the evolution of the Quick-XAS data alternatively recorded at the $\mathrm{Mo}$ and $\mathrm{Co} \mathrm{K}$ edges, respectively, upon liquid sulfidation of the dried $\mathrm{CoMoP} / \mathrm{Al}_{2} \mathrm{O}_{3}$ catalyst at 30 bar and from $50^{\circ} \mathrm{C}$ to $350^{\circ} \mathrm{C}$. The energy shift of the rising edge position at both edges, the vanishing of the pre-edge feature at the Mo $\mathrm{K}$ edge and the decrease of the Co $\mathrm{K}$ edge white line intensity are spectral evolutions ascribed to the sulfidation of both elements (Fig. S3.). The spectra sampling frequency is high in the liquid sulfidation (one merged spectra every $2.86^{\circ} \mathrm{C}$ below $190^{\circ} \mathrm{C}$ and every $1.37^{\circ} \mathrm{C}$ above $190^{\circ} \mathrm{C}$ ) and still discontinuities are observed in the successive experimental data. This feature indicates the presence of extremely fast transformation in the liquid mechanism occurring above $190^{\circ} \mathrm{C}$.

\section{Insert Figure 6.}

The Mo $\mathrm{K}$ edge XANES spectra and FT of the EXAFS spectra of the pure components extracted by MCR-ALS are presented in Figure 7. A. and C., respectively. The variance of the XAS data recorded at the Mo $\mathrm{K}$ edge during the liquid sulfidation is satisfactorily explained by a mixture of 5 different spectra (Fig. S8. to Fig. S10. in SI). The concentration profiles associated to the different spectra are presented in Figure 8 with straight lines. The 
energy position of the rising edge of the first two spectra L-Mo-C1 and L-Mo-C2 (Fig. 7.A.) and the presence of a clear pre-edge feature for these spectra together with the characteristic Mo-O contributions in their FT allow us to identify them as $\mathrm{Mo}^{\mathrm{Vl}}$ oxide compounds [23]. The Raman spectrum of the oxide phase corresponding to the L-Mo-C1 shows a mixture of several polyanions (polymolybdates and Strandberg heteropolyanions) dispersed at the surface of the catalyst (Fig. S4. in SI). Their non-isolation by MCR-ALS analysis of XAS data is indicative either that a correlated evolution of the concentrations of those polyanions occurs during the activation or that the local structures of these polyanions are too close to each other to be separated by MCR-ALS. The transformation of the oxide phase (L-Mo-C1) into the first oxide intermediate (L-Mo-C2) occurs between $50^{\circ} \mathrm{C}$ and $225^{\circ} \mathrm{C}$. This phenomenon might be due to a dehydration and/or depolymerization process of the polyanions [23]. Namely, the spectrum of the L-Mo-C2 intermediate displays a clear increase of the pre-edge intensity and of the bump of the main resonance between 20040 and $20050 \mathrm{eV}$. As already reported by some of us during the monitoring of the calcination under air of a NiMo catalyst [23], these spectral features are similar to the ones recorded for tetrahedral molybdenum oxo species like in $\mathrm{Na}_{2} \mathrm{MoO}_{4}$ [24] or $\left(\mathrm{NH}_{4}\right)_{2} \mathrm{Mo}_{2} \mathrm{O}_{7}$ [8]. The second intermediate (green curve in Figure 7. A. and C.), for which the percentage increases slowly from $75^{\circ} \mathrm{C}$ and more abruptly at $225^{\circ} \mathrm{C}$, presents a significant shift in the rising edge position in good agreement with the formation of a $\mathrm{Mo}(\mathrm{V})$ species [9] and a lengthening of distances inside the first coordination shell contributing to its FT. These features are indicative of the onset of sulfidation of the oxide precursors. Above $225^{\circ} \mathrm{C}$, the third intermediate (purple curve in Fig. 7. A. and C.) quickly appears before to be converted at $243^{\circ} \mathrm{C}$ into the final species (orange curve in Fig. 7. A. and C.). The shape of the XANES spectra for these two last species together with the intense contribution located on the not-phase corrected FT at $\approx$ $1.9 \AA$ characteristic of Mo-S bonds are related to the formation of sulfided species. In particular the final species is identified by its characteristic XAS spectrum as being $\mathrm{MoS}_{2}$ $[8,9,18,23]$. According to the evolution of the Raman spectra measured at the outlet of the cell (shown in Figures S5. and S6. in SI), the decomposition of DMDS leads to the production of $\mathrm{H}_{2} \mathrm{~S}$ and $\mathrm{CH}_{4}$ detected by their respective Raman lines, respectively at $2612 \mathrm{~cm}^{-1}$ and $2918 \mathrm{~cm}^{-1} . \mathrm{CH}_{4}$ is detected at $232 \pm 5^{\circ} \mathrm{C}$ and $\mathrm{H}_{2} \mathrm{~S}$ at $284 \pm 5^{\circ} \mathrm{C}$ (Fig. S7. in SI). It is interesting to note the delay in the detection of $\mathrm{H}_{2} \mathrm{~S}$ compared to $\mathrm{CH}_{4}\left(\sim+50^{\circ} \mathrm{C}\right)$. The MCR-ALS EXAFS spectra of the intermediate species leading to the transformation of pristine oxide precursors to $\mathrm{MoS}_{2}$ were simulated by least-square fitting procedure and results are presented in Table 2. of SI.

\section{Insert Figure 7.}

The second intermediate is satisfactorily fitted considering an oxysulfide-like structure, labelled hereafter $\mathrm{L}-\mathrm{MoO}_{a} \mathrm{~S}_{\mathrm{b}}$ (Fig. S11. A. and Table 2. in SI). Several models were tested in order to reproduce the local order around Mo depicted by the EXAFS spectrum and corresponding FT of this second intermediate. Due to the limited number of independent parameters in the fit (Nind $=11$ ) calculated according to the Nynquist criterion [25], the numbers of neighbours for each contribution were fixed in the fit. This constrained simulation is then indicative of a foreseeable structural model explaining the EXAFS spectrum of this species guided by realistic distances for Mo-ligands encountered in the literature for $\mathrm{Mo}(\mathrm{V})$ structures. The best model displayed in Scheme 1. (left side) is based on a dimeric structure with molybdenum atoms linked by oxo (at $2.04 \AA$ ) and sulfido (at $2.33 \AA$ ) bridges and displaying terminal oxygen (at $1.64 \AA$ ) and sulfur (at $2.13 \AA$ ). The dimeric model is anchored 
at the surface of alumina with a Mo-Al contribution at $2.61 \AA$. The distance between Mo centres in the dimeric model is $2.65 \AA$ which is within the range of 2.65-2.95 $\AA$ observed for binuclear oxomolybdenum(V) complexes [26-28]. The presence of Mo-O-Al contribution indicates that despite the previous depolymerization suffered by the pristine oxide species upon temperature increase, the Mo-based species is still anchored on the alumina support at this stage of the activation. The third intermediate identified as a sulfided species (labelled LMoS $_{\mathrm{x}}$ ) only displays a single contribution which is fitted with one Mo-S interaction at $2.39 \AA$ with 5.0 sulfur neighbours (Fig. S11. B. in SI). There are two possibilities for its identification. It can either be $\mathrm{MoS}_{3}$ cluster or $\mathrm{MoS}_{2}$ cluster. Actually, the Mo-Mo distance for the nearest Mo neighbours is the only discriminating feature between $\mathrm{MoS}_{3}$ and $\mathrm{MoS}_{2}$ species [29]. The lack of such contribution for ${\mathrm{L}-M o S_{x}}_{\mathrm{x}}$ might be explained by small clusters. Finally, $\mathrm{MoS}_{2}$ is formed above $243^{\circ} \mathrm{C}$ and full completion of the transformation requires the isothermal stage at $350^{\circ} \mathrm{C}$. It is simulated with a Mo-S contribution at $2.41 \AA$ and a Mo-Mo contribution at 3.19 $\AA$ (Fig. S11. C. in SI).

\section{Insert Figure 8.}

Insert Scheme 1.

The variance of the XAS data recorded at the Co $\mathrm{K}$ edge during the heating ramp of the liquid sulfidation (Fig. S12. to S14. in SI) can be explained by the 3 spectra displayed on Figure 7. B. and D.. The concentration profiles associated to the different spectra are presented in Figure 8 with dots lines and fitting results are gathered in SI (Table 3. and Fig. S15.). The first spectrum (blue curve) represents an oxide with a Co-O contribution at $2.07 \AA$ with 6.1 oxygen neighbours. The intermediate species (red curve) is also an oxide species fitted with a Co-O contribution at $2.01 \AA$ with 4 oxygen neighbours. The shortening of first coordination shell distance, the decrease of coordination numbers from 6 to 4 , together with the slight increase of pre-edge feature in the Co K edge XANES data suggests the formation of tetrahedral oxide cobalt species [30]. Similar behaviour is observed for the heating up to $220^{\circ} \mathrm{C}$ of dried CoMoP catalyst under 1 bar of $\mathrm{H}_{2}$ and could be ascribed to the diffusion of cobalt ion into the tetrahedral vacant sites of alumina support [31]. The formation of the final Co sulfided species starts at $225^{\circ} \mathrm{C}$ and is extremely fast as it ends at $250^{\circ} \mathrm{C}$. We can

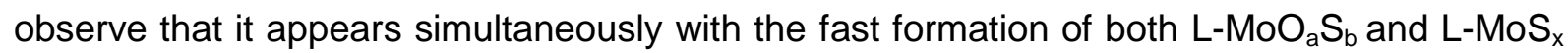
species in this temperature range (Fig. 8.). The final Co spectrum is fitted with a Co-S contribution at $2.23 \AA$, a Co-Co contribution at $2.61 \AA$ characteristic of the $\mathrm{Co}_{9} \mathrm{~S}_{8}$ phase and a Co-Mo contribution at $2.82 \AA$ attributed to the formation of the CoMoS phase [33]. These results suggest that the final Co spectrum is a mixture of $\mathrm{Co}_{9} \mathrm{~S}_{8}$ and CoMoS active phase which contributions are not discriminated with the applied chemometric method, probably because of a concomitant evolution of concentration of both species during the sulfidation step.

\subsection{Gas sulfidation}

Figure 9. A. and B. display the evolution of the Quick-XAS data alternatively recorded upon gas sulfidation of the dried CoMoP/Al $\mathrm{O}_{3}$ catalyst at the Mo and $\mathrm{Co} \mathrm{K}$ edges, respectively. As previously described for the XAS monitoring of the liquid sulfidation, the energy shift of the rising edge position at both edges and the decrease of the Co $\mathrm{K}$ edge white line intensity ascribe for the sulfidation of both elements. Although the gas sulfidation sampling is less frequent than the liquid one (one spectrum every $5.3^{\circ} \mathrm{C}$ ), no disruption in the spectral shape 
evolution is observed, indicating that a smoother transformation of species occurs upon gas sulfidation than upon liquid sulfidation.

Insert Figure 9.

The Mo $\mathrm{K}$ edge XANES spectra and FT of the EXAFS spectra of the pure components extracted by MCR-ALS are presented in Figure $10 \mathrm{~A}$. and C.. Contrary to the liquid sulfidation, only 4 spectra are required to describe the evolution of XAS data recorded at the Mo K edge upon sulfidation (Fig. S16. to S18. in SI). Both intermediate species leading to the transformation of pristine oxide precursors to $\mathrm{MoS}_{2}$ were identified by least-square fitting procedure of the corresponding MCR-ALS EXAFS spectra (Fig. S19. A. and B. in SI) for which the structural parameters are gathered in Table 4. of SI. The evolution of the relative concentrations determined by MCR-ALS at the Mo K edge is presented in Figure 11. The sulfidation begins between $25^{\circ} \mathrm{C}$ and $31^{\circ} \mathrm{C}$ just after the introduction of $\mathrm{H}_{2} \mathrm{~S}$ in the gas line by the formation of the $\mathrm{Mo}(\mathrm{V})$-based oxysulfide, labelled hereafter $\mathrm{G}-\mathrm{MoO}_{\mathrm{a}} \mathrm{S}_{\mathrm{b}}$ (green curve). This oxysulfide is described by terminal oxo ligand at $1.62 \AA$ and bridging oxo ones at $2.01 \AA$ and terminal disulfide ligands at $2.42 \AA$. The Mo-Mo distance in this oxysulfide dimeric complex is $2.78 \AA$, which is in line with the distance reported for $\mathrm{Mo}(\mathrm{V})$ based structure with sulfido bridges [32]. A structural model taking into account this local order description is proposed in Scheme 1. (right side). As for $\mathrm{L}-\mathrm{MoO}_{a} \mathrm{~S}_{\mathrm{b}}$ described for liquid sulfidation, the model displays a Mo-Al contribution suggesting again that the Mo-based species is also anchored on the alumina at this stage. The third component of gas sulfidation, labelled G-MoS 3 (purple curve), which appears above $85^{\circ} \mathrm{C}$ is identified as $\mathrm{MoS}_{3}$ with the contribution of 4.1 sulfur atoms at $2.38 \AA$ and 2.9 molybdenum at $2.80 \AA$ (Fig. S19. B. in SI) [29]. Between $160^{\circ} \mathrm{C}$ and $230^{\circ} \mathrm{C}$, the $\mathrm{MoS}_{3}$ proportion reaches a steady state suggesting that the transformation rate of the oxysulfide into $\mathrm{MoS}_{3}$ and the one of $\mathrm{MoS}_{3}$ into $\mathrm{MoS}_{2}$ are equivalent in this temperature range. As shown in Figures S24. and S25. in SI, the comparisons of the FT of the oxysulfide and sulfur intermediates before the formation of $\mathrm{MoS}_{2}$ are different depending on the activation process.

Insert Figure 10.

Insert Figure 11.

As for the liquid sulfidation, the variance contained in the evolution of the XAS spectra recorded at the Co $\mathrm{K}$ edge during gas sulfidation may be explained by 3 spectra (Fig. S20. to S22. in SI). The final sulfided phases are similar for both activation processes. The comparison of Co-C3 EXAFS spectra and FT are presented in Figure S26. of SI and their fitting results in Table 3. for liquid sulfidation and in Table 5. for gas sulfidation in SI. The Co oxide phase displays a Co-O contribution at $2.06 \AA$ with $\approx 6$ oxygen neighbours and the Co final sulfided phases share a Co-S contribution at $2.23 \AA$, a Co-Co contribution at $2.63 \AA$ and a Co-Mo contribution at $2.77 \AA$. However, the intermediate species G-Co-C2 is different to LCo-C2 which was an oxidic intermediate. The fitting result (Fig. S23. B. and Table 5. in SI) and the XANES spectrum reveal a sulfided intermediate simulated with two Co-S contributions at $2.26 \AA$ and at $3.59 \AA$ with respectively 6.0 and 1.7 sulfur neighbours. Results in the literature have shown at the early stage of gas sulfidation of $\mathrm{Co}$ or $\mathrm{Ni}$ monometallic catalysts $\left(\mathrm{T}<200^{\circ} \mathrm{C}\right)$ the presence of $\mathrm{CoS}_{2}$ [34] or $\mathrm{NiS}_{2}[23,35]$ species. Herein, our results suggest the presence of a $\mathrm{CoS}_{x}$ species which may be also related to $\mathrm{CoS}_{2}$ although the first coordination shell distance is slightly shorter than the Co-S distance $(-0.07 \AA)$ in the first coordination shell of $\mathrm{CoS}_{2}$ [36]. Between $125^{\circ} \mathrm{C}$ and $150^{\circ} \mathrm{C}, \approx 60 \%$ of G-Co-C2 is quickly 
transformed into the final G-Co-C3 species, whereas the conversion of the remaining G-Co$\mathrm{C} 2$ species is quite slow and is only complete when the temperature reaches $400^{\circ} \mathrm{C}$.

\section{Discussion}

The comparison of molybdenum speciation obtained by MCR-ALS for liquid high pressure sulfidation and atmospheric pressure gas sulfidation reveals a difference in the total number of species involved from the pristine oxides to the formation of $\mathrm{MoS}_{2}$ slabs, i.e. 4 in gas phase against 5 in liquid sulfidation. As already reported in the literature $[8,9,37,38]$, gas sulfidation proceeds in a stepwise process with nearly equivalent transformation rates as soon as the catalyst is in contact with the $\mathrm{H}_{2} \mathrm{~S} / \mathrm{H}_{2}$ feed, starting with the progressive transformation of oxide precursors at RT into an oxysulfide species (transformation rate equal to $0.8 \% /{ }^{\circ} \mathrm{C}$ ), itself transformed into $\mathrm{MoS}_{3}$ at $\mathrm{T}>85^{\circ} \mathrm{C}$ (transformation rate of $1.3 \% /{ }^{\circ} \mathrm{C}$ ) and finally $\mathrm{MoS}_{2}$ above $150^{\circ} \mathrm{C}$ (transformation rate of $0.4 \% /{ }^{\circ} \mathrm{C}$ ). Liquid sulfidation involves also a transformation sequence " $\mathrm{MoO}_{\mathrm{a}} \mathrm{S}_{\mathrm{b}} \rightarrow \mathrm{MoS}_{\mathrm{x}} \rightarrow \mathrm{MoS}_{2}$ ", but with abrupt transitions above $225^{\circ} \mathrm{C}$ and occurring in a shortened temperature interval of $23^{\circ} \mathrm{C}$ compared to $125^{\circ} \mathrm{C}$ for gas sulfidation. Texier et al. [39] studied the decomposition of DMDS $\left(\mathrm{CH}_{3}-\mathrm{S}-\mathrm{S}-\mathrm{CH}_{3}\right)$ under liquid phase sulfidation and highlighted that a sharp decomposition leading to $\mathrm{CH}_{4}$ and $\mathrm{H}_{2} \mathrm{~S}$ feed enrichment occurs above $220-230^{\circ} \mathrm{C}$. Due to the lack of high concentration of $\mathrm{H}_{2} \mathrm{~S}$ before the complete decomposition of DMDS, the liquid sulfidation goes through one more oxide intermediate species before the oxysulfide species. The delay of $\mathrm{H}_{2} \mathrm{~S}$ supply leads to a depolymerisation of the Strandberg and polyoxomolybdates oxide species present at the surface of the alumina giving rise to the formation of smaller $\mathrm{Mo}(\mathrm{VI})$ oxide clusters. In a temperature range lower than $225^{\circ} \mathrm{C}$, Texier et al. [39] reported also that DMDS is decomposed into $\mathrm{CH}_{3} \mathrm{SH}(90 \%)$, but also DMS (5\%) and methane (5\%) with concomitant formation of $\mathrm{H}_{2} \mathrm{~S}$. This early decomposition of 1 equivalent of DMDS into 0.1 equivalents of $\mathrm{H}_{2} \mathrm{~S}$ as well as the presence of light sulfur compounds in the gas oil feedstock are responsible for the early transformation of oxide species into the $\mathrm{L}-\mathrm{MoO}_{\mathrm{a}} \mathrm{S}_{\mathrm{b}}$ species with $\mathrm{a}$ formation rate of $0.2 \% /{ }^{\circ} \mathrm{C}$ up to $225^{\circ} \mathrm{C}$. At higher temperature, the massive decomposition of DMDS into $\mathrm{CH}_{4}$ and $\mathrm{H}_{2} \mathrm{~S}$ is responsible for the abrupt transformation of the L-Mo-C2 oxide species into first $\mathrm{L}-\mathrm{MoO}_{\mathrm{a}} \mathrm{S}_{\mathrm{b}}$ (transformation rate $9.2 \% /{ }^{\circ} \mathrm{C}$ ) and then into the third L-MoS $\mathrm{x}$ species (transformation rate $5.7 \% /{ }^{\circ} \mathrm{C}$ ). Regarding the gas composition monitored by Raman at the cell outlet, it is interesting to note a delay of $\sim+50^{\circ} \mathrm{C}$ between the detection of $\mathrm{CH}_{4}$ in the gas feed and the one of $\mathrm{H}_{2} \mathrm{~S}$. Considering that the formation of $\mathrm{CH}_{4}$ and $\mathrm{H}_{2} \mathrm{~S}$ resulting from DMDS decomposition is equivalent in concentration, this observation is related to the uptake of $\mathrm{H}_{2} \mathrm{~S}$ by the catalyst leading to the sulfidation of the oxidic species dispersed on alumina. Consequently, the presence of $\mathrm{H}_{2} \mathrm{~S}$ at the outlet is a strong indication that no more $\mathrm{H}_{2} \mathrm{~S}$ is required for sulfiding the sample. The temperature difference between the observation of $\mathrm{CH}_{4}$ rising and the one of $\mathrm{H}_{2} \mathrm{~S}$ perfectly matches the differences in temperature between the onset of formation of $\mathrm{L}_{-}-\mathrm{MoO}_{a} \mathrm{~S}_{\mathrm{b}}$ and the end of the cobalt sulfidation whereas $50 \%$ of $\mathrm{MoS}_{2}$ is already formed. Definitely the differences between liquid and gas sulfidation transformation rates observed for the sequences oxide $\rightarrow \mathrm{MoO}_{\mathrm{a}} \mathrm{S}_{\mathrm{b}} \rightarrow \mathrm{MoS}_{3}$-which are the only ones requiring a consumption of $\mathrm{H}_{2} \mathrm{~S}$ - are strongly dependent on the temperature at which the $\mathrm{H}_{2} \mathrm{~S}$ supply occurs but also its amount. The gas sulfidation is carried out a constant $\mathrm{H}_{2} \mathrm{~S}$ pressure of 0.15 bar whereas when DMDS is completely decomposed in $\mathrm{H}_{2} \mathrm{~S}$ there is an abrupt increase of $\mathrm{H}_{2} \mathrm{~S}$ pressure to 2.1 bar. Furthermore the fact that the massive 
release of $\mathrm{H}_{2} \mathrm{~S}$ occurs at a temperature $\left(225^{\circ} \mathrm{C}\right)$ at which trapping of $\mathrm{H}_{2} \mathrm{~S}$ by alumina surface is no more observed [34,40] is also a favorable condition for the abrupt transformation of oxide $\rightarrow \mathrm{MoO}_{\mathrm{a}} \mathrm{S}_{\mathrm{b}} \rightarrow \mathrm{MoS}_{3}$ species compared to the observed transformation rates of gas sulfidation.

The way of supplying $\mathrm{H}_{2} \mathrm{~S}$ is also of prime importance for the formation of the oxysulfide intermediate species. Indeed as shown in Scheme 1., the intermediate dimeric molybdenum (V) oxysulfide species formed upon liquid transformation is different to the one observed in gas sulfidation. Upon exposure to sulfiding atmosphere, the mechanism well admitted in the literature is first the exchange of terminal oxygen atoms by sulfur ligands without modification of Mo oxidation state and then transformation of terminal sulfido groups into terminal disulfido or bridging sulfido or disulfido between Mo centers with reduction of Mo oxidation state [41]. The proposed structures for both oxysulfide intermediates suggest that the one appeared during the liquid sulfidation is in more advanced state regarding the formation of sulfide network with exchange of bridging oxo ligands by bridging sulfide ligands or by condensation process between isolated Mo centers. The fact that this sulfidation step occurs on isolated or small tetrahedral condensed units for liquid sulfidation process could contribute to the "nucleation" of homogeneous dimeric oxysulfide intermediates $\left(9.2 \% /{ }^{\circ} \mathrm{C}\right)$ which are then further very quickly transformed into $\operatorname{MoS}_{x}\left(5.7 \% /{ }^{\circ} \mathrm{C}\right)$ limiting the spatial extension of the amorphous cluster-cluster aggregation characteristic of $\mathrm{MoS}_{x} / \mathrm{MoS}_{3}[9,42]$. This feature could explain the lack of Mo-Mo contribution observed on the FT of the liquid phase MoS $_{x}$ sulfide intermediate. This behaviour is opposite to the one observed under gaseous condition for which the growth of $\mathrm{MoS}_{3}$ occurs over an extended temperature range leading to a spatially extended amorphous structure based on aggregation of clusters with different shapes and sizes as a result of the diversity of oxide building blocks from where are formed the oxysulfide species $[9,42]$. It is noteworthy that both oxysulfide intermediates described in Scheme 1. are still anchored to the alumina through a Mo-O-Al interaction. With the formation of fully sulfided species L-MoS $x$ for liquid sulfidation or G-MoS $\mathrm{S}_{3}$ for gaseous one, the interaction with the support is lost. This appears mandatory for further transformation of $\mathrm{MoS}_{\mathrm{x}} / \mathrm{MoS}_{3}$ into $\mathrm{MoS}_{2}$ [9]. It is noteworthy that after the formation of these phases, irrespective to the activation process, the further transformation into $\mathrm{MoS}_{2}$ is done with quite similar transformation rate $\left(0.9 \% /{ }^{\circ} \mathrm{C}\right.$ for liquid one against $0.4 \% /{ }^{\circ} \mathrm{C}$ for the gas sulfidation) suggesting that at this advanced stage of sulfidation, the mechanism is governed by the same driving force, in particular the amount of $\mathrm{H}_{2} \mathrm{~S}$ in the reactant feed did not play a role in the $\mathrm{MoS}_{2}$ formation kinetic. XAS analysis of the catalysts measured at RT at the end of both activation processes shows similar Mo-Mo coordination numbers taking into account the error bars (fitting results are shown in Table 6. of SI). The liquid and gas sulfided catalysts were also analysed by TEM in order to determine the distribution of the lengths and stacking degree of $\mathrm{MoS}_{2}$ slabs (histograms and pictures available in 27. in SI). The average slab length is $2.9 \mathrm{~nm}$ and $3.5 \mathrm{~nm}$ and the average stacking degree is 1.9 and 2.1 , respectively for liquid sulfidation and gas sulfidation. No difference may be observed on the average stacking degree. However, the average slabs length is slightly increased for the gas sulfidation compared to the liquid one. Moreover, the histograms highlight that the slab length distribution is centred on the $1.5-3.5 \mathrm{~nm}$ interval with $81 \%$ of detected slabs for the liquid sulfidation against a broader interval (1.5-5.0 nm with $87 \%$ of detected slabs and of those, $26 \%$ with length higher than $3.5 \mathrm{~nm}$ ) for the gas sulfidation. This result is in good agreement with the aforementioned differences in transformation kinetics (oxysulfide $\rightarrow \operatorname{MoS}_{\mathrm{x}} \rightarrow \mathrm{MoS}_{2}$ ) observed between the activation procedures and strongly related to the increased dispersion 
of Mo species occurring at the early stage of the liquid process $\left(\mathrm{T}<225^{\circ} \mathrm{C}\right)$ and to the instantaneous nucleation of oxysulfide caused by the massive release of $\mathrm{H}_{2} \mathrm{~S}$ occurring at $\approx 225^{\circ} \mathrm{C}$. Furthermore, histograms also point out the formation of more single slabs of $\mathrm{MoS}_{2}$ in liquid sulfidation than in gas sulfidation, in agreement with literature results [33].

At the Co $\mathrm{K}$ edge, irrespective to the process, it is noteworthy that in the temperature range lower than $225^{\circ} \mathrm{C}$ the concentration profiles of the 3 cobalt species follow quite well the ones describing the first 3 Molybdenum species (Fig. 8. and 11.),. However, differences are observed on the nature of the cobalt intermediate species at the early stage of sulfidation ( $T$ $<200^{\circ} \mathrm{C}$ ). For liquid sulfidation, the Co oxide intermediate species is characterized by a 4fold coordination assumed as tetrahedral and which could be related to the diffusion of dehydrated cobalt ions to the tetrahedral vacant alumina sites. It is interesting to note that from $150^{\circ} \mathrm{C}$ till $240^{\circ} \mathrm{C}$, despite the $\mathrm{H}_{2} \mathrm{~S}$ presence in the reactant feed at low concentration, the sulfidation level of cobalt is lower than $5 \%$ against $30 \%$ for Mo. This could be related to the proposed diffusion upon heating of cobalt cations in the surface vacant tetrahedral sites of alumina letting them less accessible against sulfidation than the dispersed Mo species. In gas sulfidation, the formation of $\mathrm{CoS}_{2}$-like phase (G-Co-C2 in Fig. 11.) is observed simultaneously with the formation of $\mathrm{G}-\mathrm{MoO}_{\mathrm{a}} \mathrm{S}_{\mathrm{b}}$. During the study of gas sulfidation of $\mathrm{Co}$ and CoMo dried catalysts [34], it was shown by Raman and quick-XAS that $\mathrm{CoS}_{2}$-like species are formed and are easily and quickly converted into $\mathrm{Co}_{9} \mathrm{~S}_{8}$ at higher temperature indicating that the $\mathrm{CoS}_{2}$-like intermediate is thermodynamically unstable at high temperature. The liquid sulfidation avoids the formation of this sulfided intermediate insofar the decomposition of DMDS occurs at a temperature higher than the transformation temperature of $\mathrm{CoS}_{2}$ into $\mathrm{Co}_{9} \mathrm{~S}_{8}$. During liquid sulfidation, it is observed that when the $\mathrm{L}-\mathrm{MoO}_{\mathrm{a}} \mathrm{S}_{\mathrm{b}}$ oxysulfide is formed, the $\mathrm{L}-\mathrm{Co}-\mathrm{C}_{2}$ oxide species is converted into the final $\mathrm{L}-\mathrm{Co}_{\mathrm{O}} \mathrm{C}_{3}$ sulfide species and most of the amount of the $\mathrm{L}-\mathrm{Co}-\mathrm{C}_{3}$ sulfide species is formed concomitantly with the formation of $\mathrm{MoS}_{\mathrm{x}}$ at $243^{\circ} \mathrm{C}$. Actually, the concomitant formation of the final cobalt sulfide species and $\mathrm{MoS}_{\mathrm{x}}$ or $\mathrm{MoS}_{3}$ is a common observation for both activation routes. This strongly supports the idea proposed by Rochet et al. [9] that the interaction between the promotor and Mo occurs when the $\mathrm{MoS}_{3}$ species are formed and does not require the formation of $\mathrm{MoS}_{2}$. As a matter of fact, the cobalt is fully sulfided (95\%) at the onset of formation of $\mathrm{MoS}_{2}$ for the liquid sulfidation.

\section{Conclusion}

In this work, we have reported the validation and the first results of a new capillary reactor for in situ XAS characterization (at E $>7.0 \mathrm{keV}$ ) of heterogeneous catalysts. This analytical cell enables the in situ Quick-XAS monitoring of the liquid sulfidation of an HDS catalyst under a real feedstock. The reactor allows high pressure (30 bar) and high temperature $\left(350{ }^{\circ} \mathrm{C}\right)$ reactions to reproduce the harsh industrial conditions of the sulfidation with the use of a glassy carbon tube. The simultaneous study at the Co and Mo $\mathrm{K}$ edge was possible, due to the unique "edge jumping" capabilities of the ROCK beamline at the SOLEIL Synchrotron. The first Quick-EXAFS results gained with the use of this reactor and analysed by MCR-ALS highlight different sulfidation mechanisms between the liquid and the gas sulfidation procedures. Indeed, liquid sulfidation modifies the number of intermediate species at the Mo $\mathrm{K}$ edge and the nature of the intermediate species at the Co $\mathrm{K}$ edge but also the transformation kinetic of the sequence "oxysulfide $\rightarrow \mathrm{MoS}_{\mathrm{x}}$ or $\mathrm{MoS}_{3}$ ". At the Mo $\mathrm{K}$ edge, the heating of pristine oxide species under 30 bar of $\mathrm{H}_{2}$ and with a mixture of gas oil and DMDS 
up to $225^{\circ} \mathrm{C}$ leads first to the formation of well dispersed and depolymerized oxide species on the surface of the alumina. With the massive release of $\mathrm{H}_{2} \mathrm{~S}$ at $225^{\circ} \mathrm{C}$, quasi instantaneous nucleation of oxysulfide and then $\mathrm{MoS}_{\mathrm{x}}$ species occur and could be the driving force leading to the slight morphology differences observed by TEM on the final $\mathrm{MoS}_{2}$ phase depending on the activation route, i.e. smaller slabs, less size dispersed for liquid sulfidation. At the Co $\mathrm{K}$ edge, the intermediate species is an oxide species in liquid sulfidation whereas at the early stage of gas sulfidation $\mathrm{CoS}_{2}$-like species is formed. Irrespective to the sulfidation processes, the intermediate cobalt species is subsequently transformed into a mixture of $\mathrm{Co}_{9} \mathrm{~S}_{8}$ and CoMoS in synergy with the formation of the $\mathrm{MoS}_{3} / \mathrm{MoS}_{\mathrm{x}}$ intermediates suggesting that promotion of Mo is achieved at this stage.

This new capillary reactor will be a powerful tool to study the liquid sulfidation of additivated HDS catalysts in order to unravel the effect of different organic additives on the industrial sulfidation mechanism. The effect of organic additives was widely studied in the literature using gas sulfidation activation [43-47]. However, our results show that intermediate species and mechanisms supporting their transformations depend on the activation process. Therefore, extrapolation of results gained for gas sulfidation may be delicate and irrelevant for explaining industrial conditions (high pressure, liquid phase, delayed supply of $\mathrm{H}_{2} \mathrm{~S} \ldots$ ) and studies using liquid sulfidation are mandatory.

\section{Acknowledgements}

This work was supported by a public grant overseen by the French National Research Agency (ANR) as a part of the "Investissements d'Avenir" (ref: ANR-10-EQPX-45) provided for the building of the ROCK beamline. The authors want to thank also SOLEIL for providing beamtime at the ROCK beamline. We also want to address special thanks to L. Barthe, D. Suire, M. Rolland, M. Duarte de Sousa and the IFPEN design department for their advices and the design of the cell.

\section{References}

[1] H. Topsøe, B.S. Clausen, F.E. Massoth, in: J.R. Anderson, M. Boudart (Eds.), Catalysis: Science and Technology, Springer Berlin Heidelberg, Berlin, Heidelberg, 1996, pp. 1-269.

[2] B. Rebours, R. Revel, A.A. Quoineaud, in: H. Toulhoat, P. Raybaud (Eds.), Catalysis by transition metal sulphides: From molecular theory to industrial application, Éd. Technip, Paris, 2013, ch. 2.6 p. 376-386.

[3] C. Lamonier, E. Payen, in: H. Toulhoat, P. Raybaud (Eds.), Catalysis by transition metal sulphides: From molecular theory to industrial application, Éd. Technip, Paris, 2013, ch. 2.2 p. 151-181.

[4] S. Texier, G. Berhault, G. Pérot, F. Diehl, Applied Catalysis A: General 293 (2005) 105-119.

[5] N. Frizi, P. Blanchard, E. Payen, P. Baranek, C. Lancelot, M. Rebeilleau, C. Dupuy, J.P. Dath, Catalysis Today 130 (2008) 32-40.

[6] N. Frizi, P. Blanchard, E. Payen, P. Baranek, M. Rebeilleau, C. Dupuy, J.P. Dath, Catalysis Today 130 (2008) 272-282.

[7] S. Eijsbouts, L. van den Oetelaar, J.N. Louwen, R.R. van Puijenbroek, G.C. van Leerdam, Industrial \& Engineering Chemistry Research 46 (2007) 3945-3954. 
[8] A. Rochet, B. Baubet, V. Moizan, C. Pichon, V. Briois, Comptes Rendus Chimie 19 (2016) 13371351.

[9] A. Rochet, B. Baubet, V. Moizan, E. Devers, A. Hugon, C. Pichon, E. Payen, V. Briois, J. Phys. Chem. C 121 (2017) 18544-18556.

[10] L. van Haandel, E. Hensen, T. Weber, Catalysis Today 292 (2017) 51-57.

[11] V. Briois, C. La Fontaine, S. Belin, L. Barthe, T. Moreno, V. Pinty, A. Carcy, R. Girardot, E. Fonda, Journal of Physics: Conference Series 712 (2016) 12149.

[12] E. Fonda, A. Rochet, M. Ribbens, L. Barthe, S. Belin, V. Briois, Journal of synchrotron radiation 19 (2012) 417-424.

[13] C. La Fontaine, L. Barthe, A. Rochet, V. Briois, Catalysis Today 205 (2013) 148-158.

[14] S. Reschke, K. Sigfridsson, P. Kaufmann, N. Leidel, S. Horn, K. Gast, C. Schulzke, M. Haumann, S. Leimkühler, The Journal of Biological Chemistry 288 (2013) 29736-29745.

[15] A.C. Thompson, D.T. Attwood, E.M. Gullikson, Howells, K.J. Kim, J. Kirz, J.B. Kortright, I. Lindau, P. Pianetta, A.L. Robinson, Vaughan. Berkeley: Lawrence Berkeley National Laboratory (2001).

[16] J. Jaumot, A. de Juan, R. Tauler, Chemometrics and Intelligent Laboratory Systems (2015) 112.

[17] J. Jaumot, R. Gargallo, A. de Juan, R. Tauler, Chemometrics and Intelligent Laboratory Systems 76 (2005) 101-110.

[18] V. Petkov, S.J.L. Billinge, P. Larson, S.D. Mahanti, T. Vogt, K.K. Rangan, M.G. Kanatzidis, Phys. Rev. B 65 (2002) 92105.

[19] E. Shimao, Bulletin of the Chemical Society of Japan 40 (1967) 1609-1613.

[20] L. Kihlborg, Arkiv for Kemi (1963) 357-364.

[21] R.W. Wyckoff, Crystal structures 1 (1963) 85-237.

[22] Q. Zhao, H.J. Kulik, Journal of Chemical Theory and Computation 14 (2018) 670-683.

[23] A. Rochet, B. Baubet, V. Moizan, E. Devers, A. Hugon, C. Pichon, E. Payen, V. Briois, The Journal of Physical Chemistry C 119 (2015) 23928-23942.

[24] A. Tougerti, E. Berrier, A.-S. Mamede, C. La Fontaine, V. Briois, Y. Joly, E. Payen, J.-F. Paul, S. Cristol, Angewandte Chemie (International ed. in English) 52 (2013) 6440-6444.

[25] E.A. Stern, Phys. Rev. B 48 (1993) 9825-9827.

[26] J. Mitra, S. Sarkar, Indian Journal of chemistry (2011) 401-408.

[27] I.G. Dance, A.E. Landers, Inorganic Chemistry 18 (1979) 3487-3492.

[28] L. Ma, S. Liu, H. Zhu, J. Zubieta, Polyhedron 8 (1989) 669-675.

[29] S.J. Hibble, D.A. Rice, D.M. Pickup, M.P. Beer, Inorganic Chemistry 34 (1995) 5109-5113.

[30] V. Briois, R.M. Lequan, M. Lequan, C. Cartier, G. van der Laan, A. Michalowicz, M. Verdaguer, Chemistry of Materials 4 (1992) 484-493.

[31] L. Samain, A. Jaworski, M. Edén, D.M. Ladd, D.K. Seo, F. Javier Garcia-Garcia, U. Häussermann, Journal of Solid State Chemistry 217 (2014) 1-8.

[32] A. Müller, Polyhedron 5 (1986) 323-340.

[33] L. van Haandel, G.M. Bremmer, E.J.M. Hensen, T. Weber, Journal of Catalysis 342 (2016) 2739.

[34] L. Plais, Catalyseurs d'hydrotraitement Mo/Al2O3 doublement promus préparés à partir d'hétéropolyanions d'Anderson Suivi de la sulfuration par Quick-EXAFS (2017), Université de Lille 1. 
[35] A. Rochet, A. Ribeiro Passos, C. Legens, V. Briois, Catalysis, Structure \& Reactivity 3 (2017) 33-42.

[36] E. Nowack, D. Schwarzenbach, T. Hahn, Acta Crystallogr B Struct Sci 47 (1991) 650-659.

[37] R. Cattaneo, F. Rota, R. Prins, Journal of Catalysis 199 (2001) 318-327.

[38] R. Cattaneo, T. Weber, T. Shido, R. Prins, Journal of Catalysis 191 (2000) 225-236.

[39] S. Texier, G. Berhault, G. Pérot, V. Harlé, F. Diehl, Journal of Catalysis 223 (2004) 404-418.

[40] P. Arnoldy, Journal of Catalysis 92 (1985) 35-55.

[41] R.G. Leliveld, A.J. van Dillen, J.W. Geus, D.C. Koningsberger, Journal of Catalysis 171 (1997) 115-129.

[42] T. Weber, J.C. Muijsers, J.W. Niemantsverdriet, The Journal of Physical Chemistry 99 (1995) 9194-9200.

[43] T. Shimizu, K. Hiroshima, T. Honma, T. Mochizuki, M. Yamada, Catalysis Today 45 (1998) 271276.

[44] O.V. Klimov, A.V. Pashigreva, M.A. Fedotov, D.I. Kochubey, Y.A. Chesalov, G.A. Bukhtiyarova, A.S. Noskov, Journal of Molecular Catalysis A: Chemical 322 (2010) 80-89.

[45] N. Rinaldi, Usman, K. Al-Dalama, T. Kubota, Y. Okamoto, Applied Catalysis A: General 360 (2009) 130-136.

[46] D. Nicosia, R. Prins, Journal of Catalysis (2005) 259-268.

[47] L. van Haandel, G.M. Bremmer, E. Hensen, T. Weber, Journal of Catalysis 351 (2017) 95-106. 


\section{Figure Caption}

Figure 1. Overview of the cell

Figure 2. Inside view of the connection between the reactor and the reactant supply

Figure 3. Slide view of the reactor

Figure 4. Gas/liquid distribution system

Figure 5. Acquisition sequence

Figure 6. Evolution of the experimental Quick-XAS spectra at the Mo K edge (A.) and the Co K edge (B.) recorded at 30 bar during the heating ramp of the liquid sulfidation of a dried CoMoP catalyst. The temperature increases from the deep blue colour $\left(50^{\circ} \mathrm{C}\right)$ to the deep red one $\left(350^{\circ} \mathrm{C}\right)$. The black line is related to the spectra recorded at $190^{\circ} \mathrm{C}$.

Figure 7. XANES spectra and FT of the EXAFS spectra associated to the MCR-ALS components determined from the analysis of the data recorded at the Mo K edge (A. and C.) and the Co K edge (B. and D.) upon the heating ramp of the liquid sulfidation of the dried CoMoP catalyst.

Figure 8. Evolution of the relative concentrations of the Mo and Co species identified by MCR-ALS during the liquid sulfidation process

Figure 9. Evolution of the experimental Quick-XAS spectra at the Mo K edge (A.) and the Co $K$ edge (B.) recorded during the heating ramp of the gas sulfidation of a dried CoMoP catalyst. The temperature increases from the deep blue colour $\left(30^{\circ} \mathrm{C}\right)$ to the deep red one $\left(400^{\circ} \mathrm{C}\right)$.

Figure 10. XANES spectra and Fourier transforms of the EXAFS spectra associated to the MCR-ALS components determined from the analysis of the data recorded at the Mo K edge (A. and C.) and the Co K edge (B. and D.) upon the heating ramp of the gas sulfidation of the dried CoMoP catalyst.

Figure 11. Evolution of the relative concentrations of the Mo and Co species identified by MCR-ALS during the gas sulfidation step

\section{Scheme Caption}

Scheme 1. Structure of the oxysulfide intermediate as a function of the activation process 
Figure 1. Overview of the cell

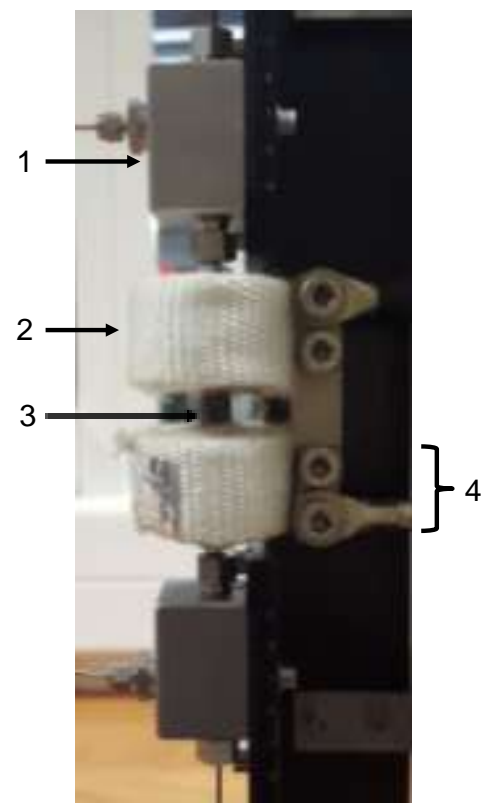

1. Connection block (Figure 2)

2. Mineral fiber ribbon

3. Oven surrounding the reactor

4. Power supply and mechanical connection

Figure 2. Inside view of the connection between the reactor and the reactant supply

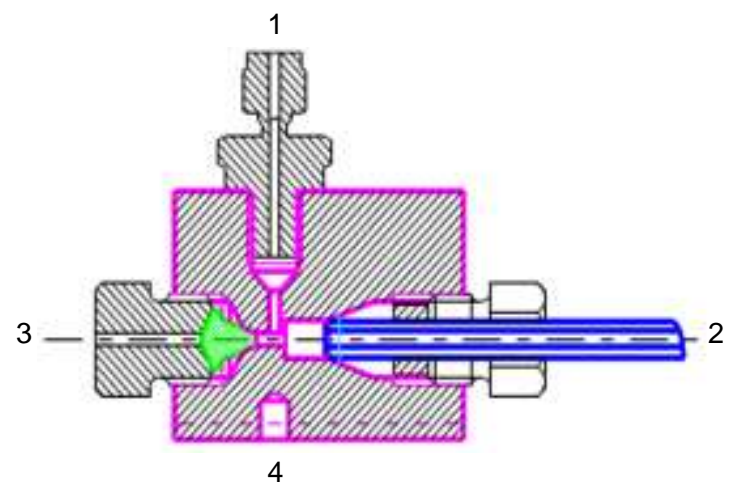

1. Entrance or exit of the reactants

2. To the reactor

3. Thermocouple

4. Screw to hold the block on the gallows 
Figure 3. Slide view of the reactor

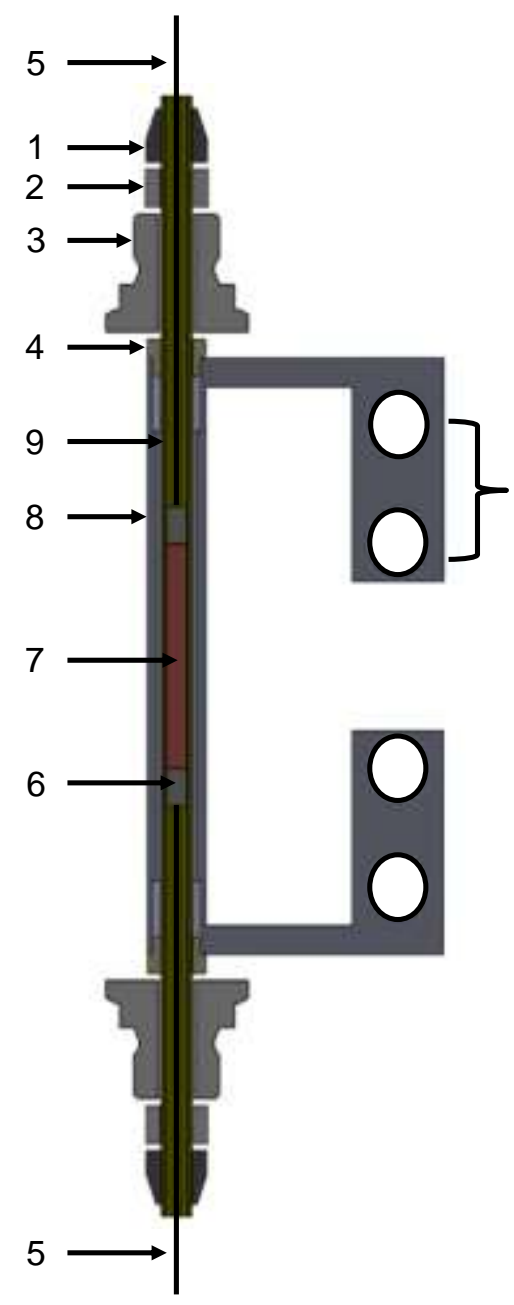

1. Vespel/graphite ferrule

102 . Stainless steel insert

3. Connector

4. Quartz or alumina insert

5. Thermocouple

6. Quartz wool

7. Sample

8. Oven

9. Glassy carbon tube

10. Power supply and mechanic connection

Figure 4. Gas/liquid distribution system

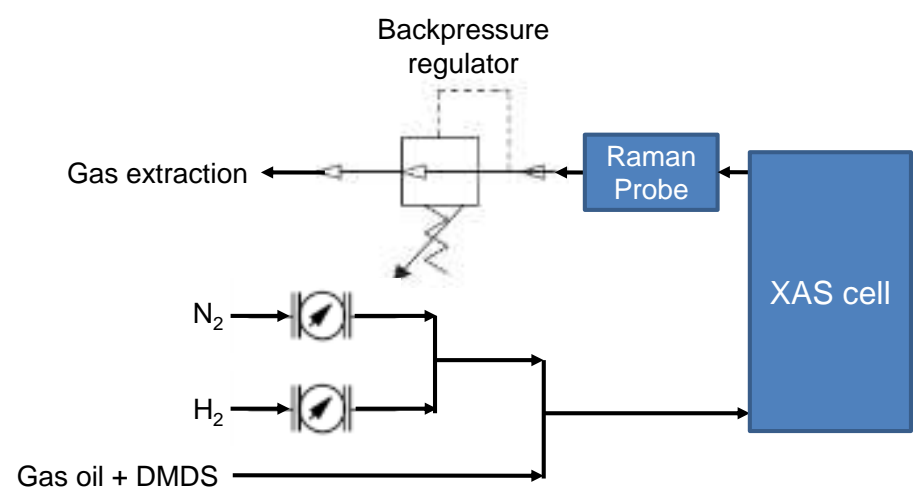

Figure 5. Acquisition sequence

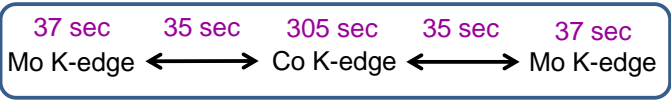


Figure 6. Evolution of the experimental Quick-XAS spectra at the Mo K edge (A.) and the Co K edge (B.) recorded at 30 bar during the heating ramp of the liquid sulfidation of the dried CoMoP catalyst. The temperature increases from the deep blue colour $\left(50^{\circ} \mathrm{C}\right)$ to the deep red one $\left(350^{\circ} \mathrm{C}\right)$. The black line is related to the spectra recorded at $190^{\circ} \mathrm{C}$.
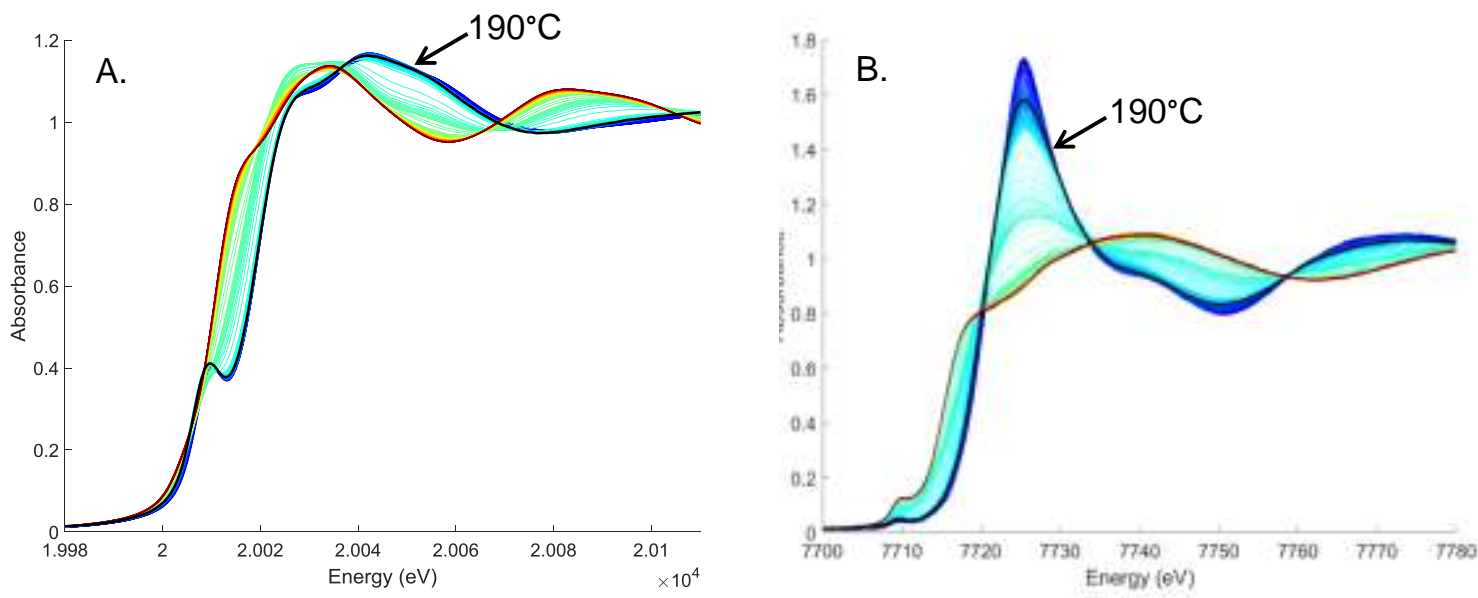

Figure 7. XANES spectra and Fourier transforms of the EXAFS spectra associated to the MCR-ALS components determined from the analysis of the data recorded at the Mo $\mathrm{K}$ edge (A. and $\mathrm{C}$.) and the Co K edge (B. and D.) upon the heating ramp of the liquid sulfidation of the dried CoMoP catalyst.
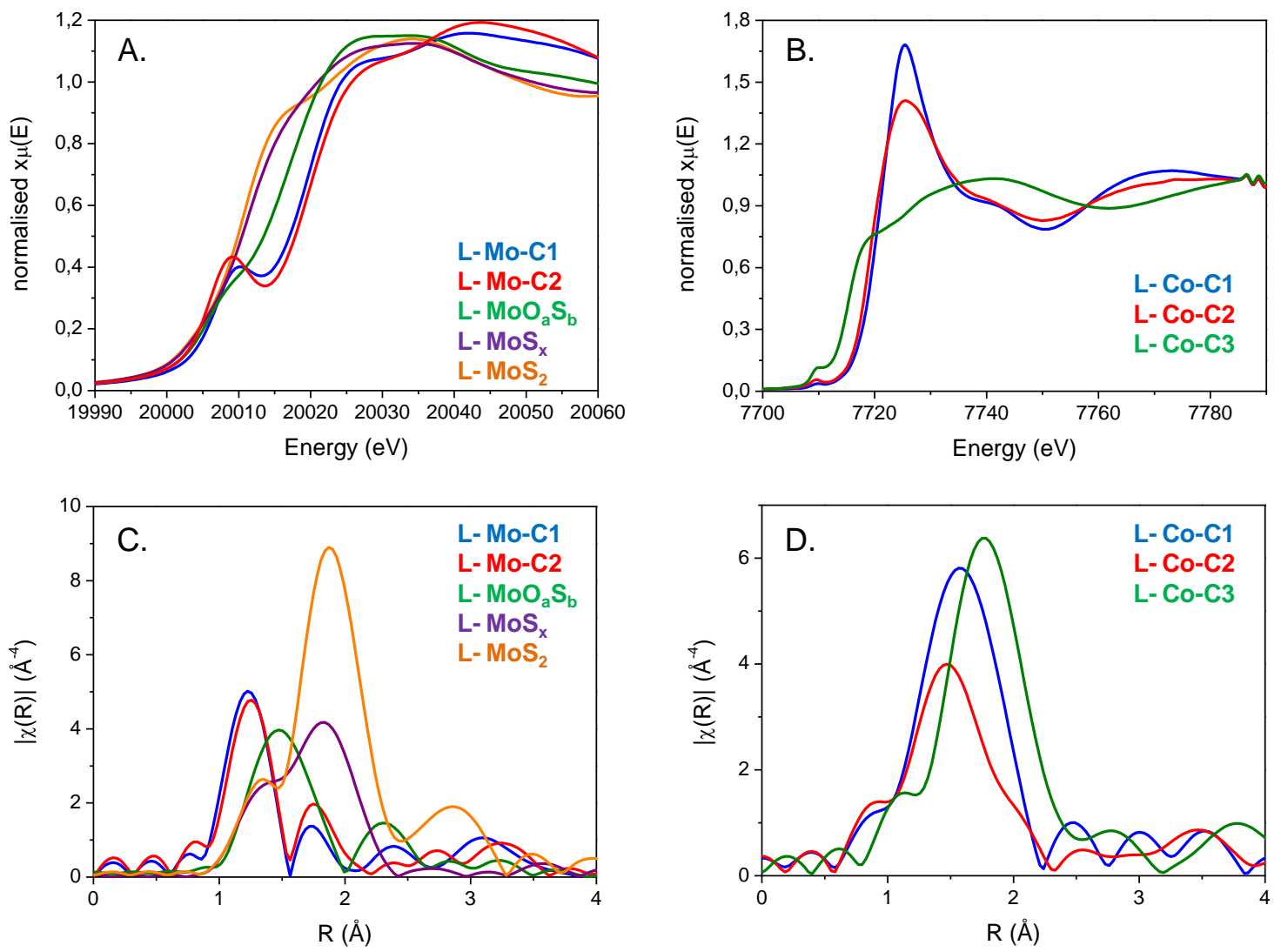
Figure 8. Evolution of the relative concentrations of the Mo and Co species identified by MCR-ALS during the liquid sulfidation process

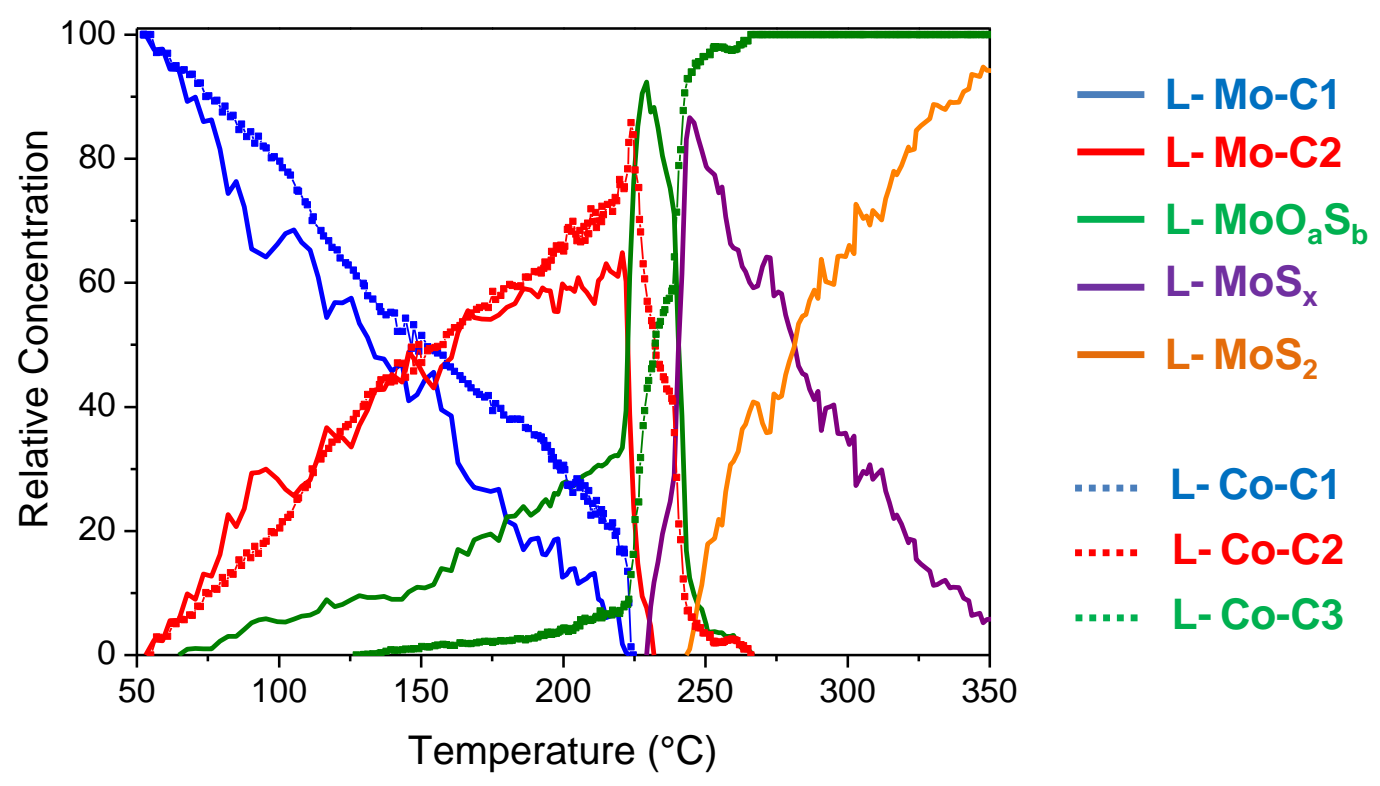

Figure 9. Evolution of the experimental Quick-XAS spectra at the Mo K edge (A.) and the Co $K$ edge (B.) recorded during the heating ramp of the gas sulfidation of the dried CoMoP catalyst. The temperature increases from the deep blue colour $\left(30^{\circ} \mathrm{C}\right)$ to the deep red one $\left(400^{\circ} \mathrm{C}\right)$.
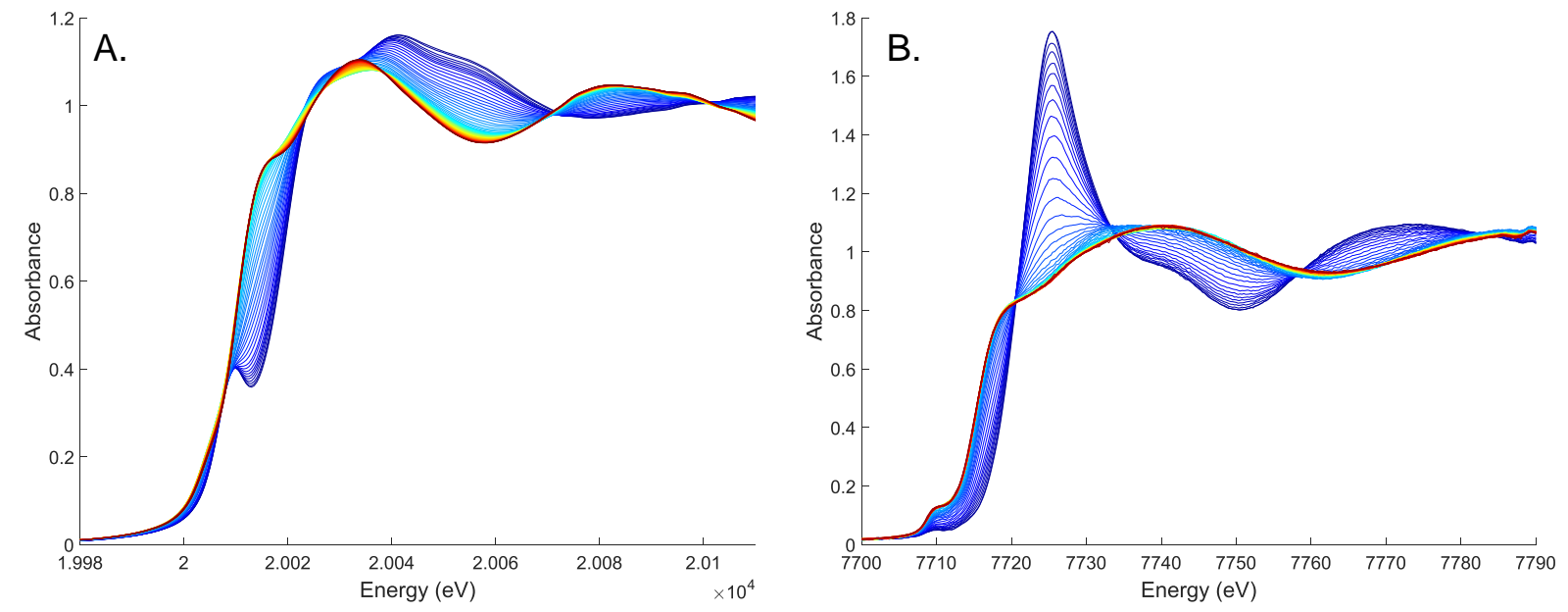
Figure 10. XANES spectra and Fourier transforms of the EXAFS spectra associated to the MCR-ALS components determined from the analysis of the data recorded at the Mo K edge (A. and C.) and the Co K edge (B. and D.) upon the heating ramp of the gas sulfidation of the dried CoMoP catalyst.
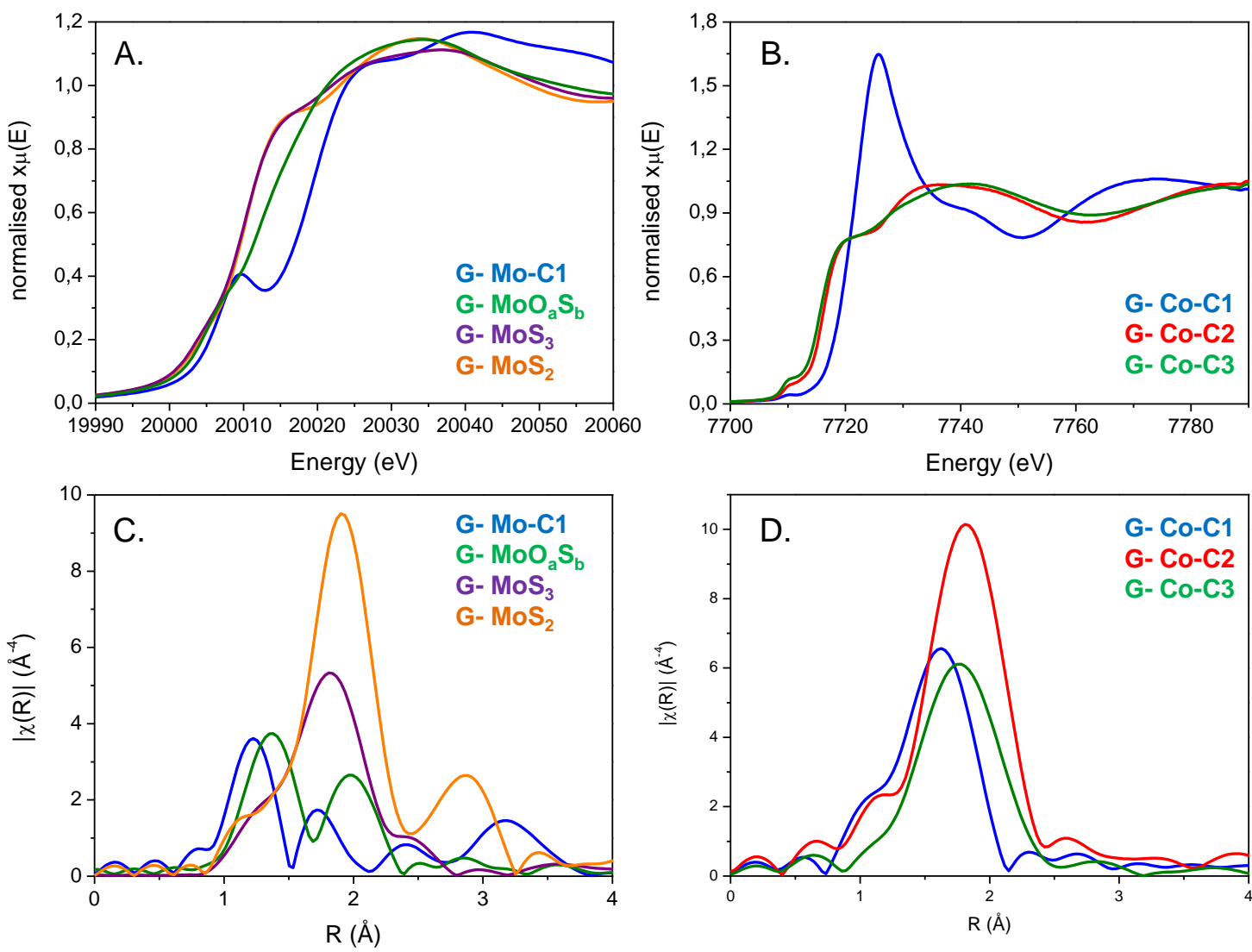

Figure 11. Evolution of the relative concentrations of the Mo and Co species identified by MCR-ALS during the gas sulfidation step

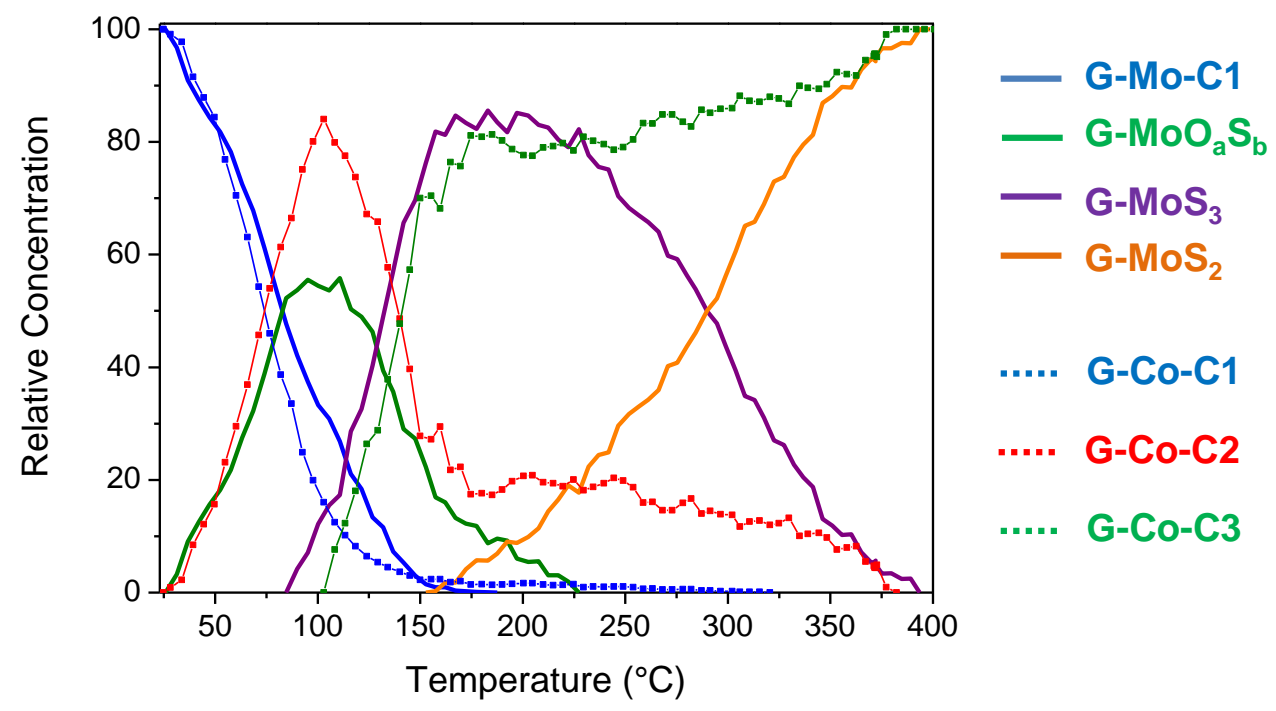


Scheme 1. Structure of the oxysulfide intermediate as a function of the activation process

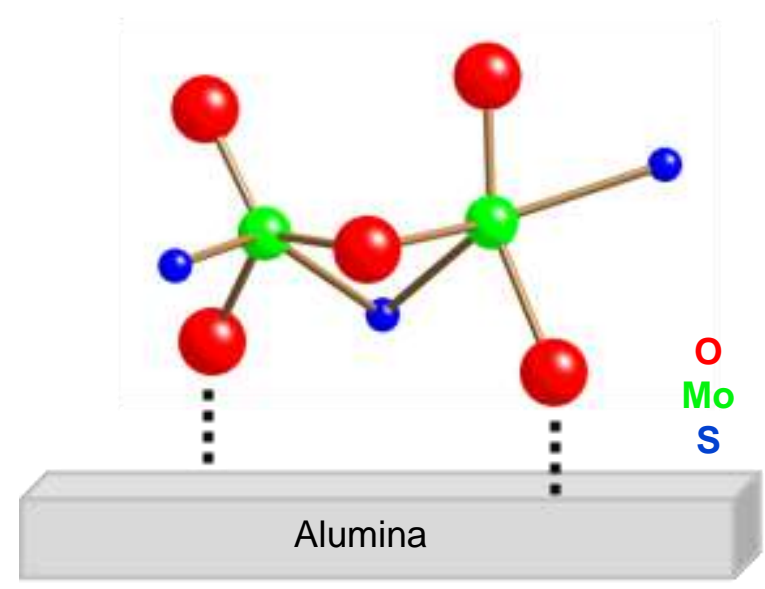

Liquid Sulfidation

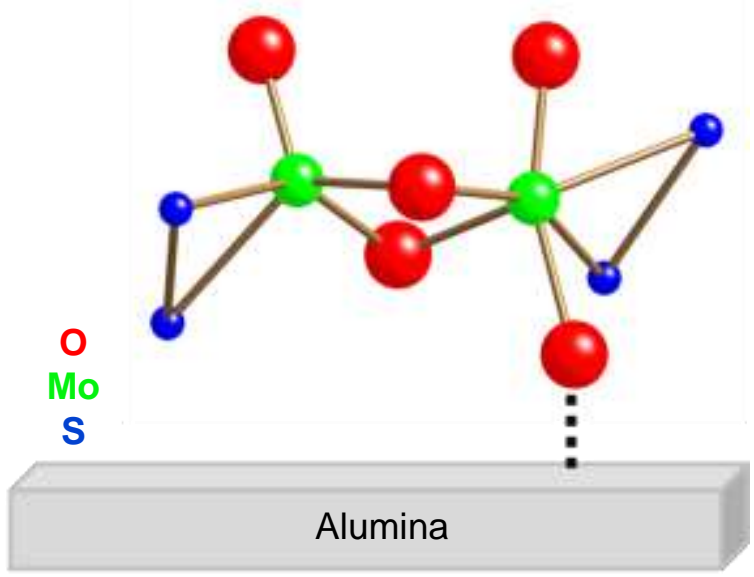

Gas Sulfidation 